\title{
Barley genotypic -glucan variation combined with enzymatic modifications direct its potential as a natural ingredient in a high fiber extract
}

Mikkelsen, Mette S.; Meier, Sebastian; Jensen, Morten G.; Qin, Fen; Stoica, Iuliana-Madalina; Martens, Helle J.; Blennow, Andreas; Jespersen, Birthe M.

Published in:

Journal of Cereal Science

Link to article, DOI:

10.1016/j.jcs.2017.02.003

Publication date:

2017

Document Version

Peer reviewed version

Link back to DTU Orbit

Citation $(A P A)$ :

Mikkelsen, M. S., Meier, S., Jensen, M. G., Qin, F., Stoica, I-M., Martens, H. J., Blennow, A., \& Jespersen, B. M. (2017). Barley genotypic -glucan variation combined with enzymatic modifications direct its potential as a natural ingredient in a high fiber extract. Journal of Cereal Science, 75, 45-53. https://doi.org/10.1016/j.jcs.2017.02.003

\section{General rights}

Copyright and moral rights for the publications made accessible in the public portal are retained by the authors and/or other copyright owners and it is a condition of accessing publications that users recognise and abide by the legal requirements associated with these rights.

- Users may download and print one copy of any publication from the public portal for the purpose of private study or research.

- You may not further distribute the material or use it for any profit-making activity or commercial gain

- You may freely distribute the URL identifying the publication in the public portal 


\section{Accepted Manuscript}

Barley genotypic $\beta$-glucan variation combined with enzymatic modifications direct its potential as a natural ingredient in a high fiber extract

Mette S. Mikkelsen, Sebastian Meier, Morten G. Jensen, Fen Qin, Iuliana-Madalina Stoica, Helle J. Martens, Andreas Blennow, Birthe M. Jespersen

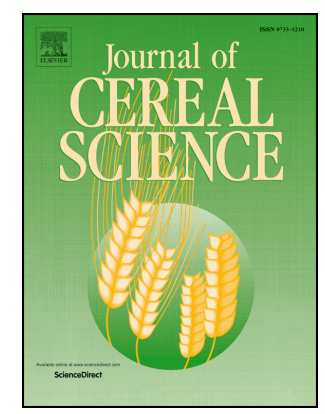

PII:

S0733-5210(16)30327-7

DOI:

10.1016/j.jcs.2017.02.003

Reference: YJCRS 2286

To appear in: Journal of Cereal Science

Received Date: 5 October 2016

Revised Date: 3 February 2017

Accepted Date: 4 February 2017

Please cite this article as: Mikkelsen, M.S., Meier, S., Jensen, M.G., Qin, F., Stoica, I.-M., Martens, H.J., Blennow, A., Jespersen, B.M., Barley genotypic $\beta$-glucan variation combined with enzymatic modifications direct its potential as a natural ingredient in a high fiber extract, Journal of Cereal Science (2017), doi: 10.1016/j.jcs.2017.02.003.

This is a PDF file of an unedited manuscript that has been accepted for publication. As a service to our customers we are providing this early version of the manuscript. The manuscript will undergo copyediting, typesetting, and review of the resulting proof before it is published in its final form. Please note that during the production process errors may be discovered which could affect the content, and all legal disclaimers that apply to the journal pertain. 


\section{Barley genotypic $\beta$-glucan variation combined with enzymatic modifications}

2 direct its potential as a natural ingredient in a high fiber extract

3

4 Mette S. Mikkelsen ${ }^{1}$, Sebastian Meier ${ }^{2}$, Morten G. Jensen ${ }^{3}$, Fen Qin ${ }^{3}$, Iuliana-Madalina Stoica ${ }^{1}$, $5 \quad$ Helle J. Martens ${ }^{4}$, Andreas Blennow ${ }^{4}$, Birthe M. Jespersen ${ }^{1}$

6

7

$8{ }^{1}$ Department of Food Science, Faculty of Science, University of Copenhagen, Rolighedsvej 26,

9 DK-1958 Frederiksberg C, Denmark

$10{ }^{2}$ Department of Chemistry, Technical University of Denmark, Kemitorvet, Building 207, DK-2800

11 Kongens Lyngby, Denmark

$12{ }^{3}$ Carlsberg Research Laboratory, Gamle Carlsberg Vej 4, DK-1799 Copenhagen V, Denmark

$13{ }^{4}$ Department of Plant and Environmental Sciences, Faculty of Science, University of Copenhagen,

14 Thorvaldsensvej 40, DK-1871 Frederiksberg C, Denmark

15

16

17 *Corresponding author:

18 Mette Skau Mikkelsen, PhD, Assistant Professor

19 Department of Food Science, Faculty of Science,

20 University of Copenhagen,

21 Rolighedsvej 26, DK-1958 Frederiksberg C, Denmark

22 Phone: +45 353329 77, e-mail: skau@food.ku.dk 


\section{ABSTRACT}

$25 \beta$-Glucan was extracted from eight different barley genotypes varying in $\beta$-glucan content and

molecular structure using Termamyl ${ }^{\circledR} \mathrm{SC}(\mathrm{T})$, Attenuzyme ${ }^{\circledR}(\mathrm{A})$ and Attenuzyme ${ }^{\circledR}$ Flex (AF) amylolytic enzymes in combinations. Extracts from barley lines Lys5f, KVL408, KVL1104 and CDC Fibar exceeded 4 g $\beta$-glucan/l, providing European Food Safety Authority (EFSA) and U.S. Food and Drug Administration (FDA) recommended amounts (3 g $\beta$-glucan/day) from three portions. TAF extracts of Lys5f and KVL408 grains reached extraordinary high concentrations of 8$9 \mathrm{~g} \beta$-glucan $/ 1$. The $\beta$-glucan molecular mass decreased with enzyme treatment $\mathrm{T}<\mathrm{TA}<\mathrm{TAF}$ due to minor lichenase side activity. Extractability was generally higher and molecular mass lower for barley lines low in triosyl/tetraosyl (DP3/DP4) ratios than for those high in DP3/DP4 ratios (Lys5f, KVL408 and KVL1104). Overall, the higher $\beta$-glucan content and structural robustness in Lys5f and KVL408 raw materials favor these in a $\beta$-glucan rich extract with potential for EFSA and FDA health and nutrition claims.

Keywords

Barley beta-glucans; Extractability; Molecular structure; Enzymatic hydrolysis 


\section{Introduction}

The human population at large fails to consume adequate amounts of dietary fiber. Recently, renewed interest in barley as a food grain has evolved due to its high content of physiologically active soluble fibers, especially mixed linkage $(1 \rightarrow 3,1 \rightarrow 4) \beta$-glucan $(B G)$.

BG dietary fibers have a remarkable range of health benefits including the promotion of heart health, stabilization of blood glucose levels, stimulation of immune responses, satiety increase and maintenance of body weight (El et al., 2012; Mikkelsen et al., 2014; Wood, 2010). Scientific evidence has led to the approval of barley BG with health claims by the United States Food and Drug Administration (FDA, 2005) and the European Food Safety Authority (EFSA). EFSA has authorized health claims for the ability of barley BG to maintain or reduce blood cholesterol levels and reduce post-prandial glycemic responses (Harland, 2014). Furthermore, barley grain fibers are approved by EFSA for contributing to an increase in fecal bulk, which relates to gut health. The recommended intake of $\mathrm{BG}$ is minimum $3 \mathrm{~g}$ per day and the health claims allow food producers to label products containing at least $1 \mathrm{~g} \mathrm{BG}$ per serving. In addition to the content of $\mathrm{BG}$ in the products, also the physico-chemical properties of BG, which may be dependent on combinations of molecular mass, solubility and viscosity, are essential for providing the health effects (Mikkelsen et al., 2014; Wood, 2010). BG depolymerization, as might be imparted by food processing, typically leads to reduction in BG viscosity. However, low molecular mass BGs have shown to form gel like structures more readily than high molecular mass BGs (Wood et al., 2010), and low molecular mass BGs might be physiologically as effective as those with high molecular mass provided that the concentration or active dose estimated by increased releasability is sufficiently high (Frank et al., 2004; Naumann et al., 2006). Kerckhoffs et al. (2003) found that beneficial physiological effects of BGs can be decreased when incorporated into solid foods such as bread and cookies. Liquid matrices, such as beverages and soups, may therefore be preferable for inducing health effects from BG meals as the liquid state allows hydration and release of the BG before ingestion. Liquids 
containing high levels of BGs are typically very viscous, which renders them less attractive as beverages. Hence, there is an unmet need for methods and materials for preparing appealing and functional extracts with high content of natural BG and there is sparse evidence of how combined processing and genotypic variation in barley BG structure affect its major physical and potential health beneficial properties. In the present study, we evaluate the extractability and quality of BG liquid formulations from eight different barley lines using mashing protocols and selected combinations of amylolytic enzymes.

In barley grains, BG is located in pericarp, scutellum, aleurone layer and starchy endosperm as a cell wall component (Dornez et al., 2011). BG is a structural polysaccharide, but it also provides glucose during grain germination (Burton et al., 2010). Barley is a genetically diverse cereal crop and it is classified as spring or winter type, two- or six-rowed, hulled or hull-less, and malting or feed by the end-use type. Based on grain composition, barley can be further classified as normal, waxy or high amylose starch types, high lysine and high BG. De-hulling and pearling of barley grains reduces the contents of insoluble fiber, protein, ash and free lipids from the outer layers including the hull (palea and lemma), bran (pericarp, testa, aleurone) and germ (embryo), and increases the content of starch and soluble BG fiber originating from the endosperm (Baik and Ullrich, 2008). BG content in barley grains typically ranges from $2.5 \%$ to $12 \%$ by weight (Izydorczyk and Dexter, 2008), but extreme levels of 15-20\% have been reported for the high BG/low starch mutant line Lys5f (Munck et al., 2004). This mutant line along with its barley mother line, Bomi, was included in the present study.

BGs are comprised of glucose units connected by $\beta(1 \rightarrow 4)$-linkages $(\sim 70 \%)$ and $\beta(1 \rightarrow 3)$ linkages $(\sim 30 \%)$ in a linear manner (Mikkelsen et al., 2010). Blocks of $\beta(1 \rightarrow 4)$-linked sequences, with cellotriose and cellotetraose units constituting $\sim 90 \%$ of the molecule, are separated by single $\beta$ $(1 \rightarrow 3$ )-linkages (Burton et al., 2010). The molar ratio of the cellotriosyl to cellotetraosyl units with degree of polymerization (DP) of 3 to 4 , respectively, is referred to as the DP3/DP4 ratio and is 
considered as a fingerprint of the individual BGs from various barley lines and tissues. Typically, small amounts $(\sim 10 \%)$ of cellulosic oligosaccharides with DP5-15 are also present (Woodward et al., 1988). DP3/DP4 ratios of barley BGs have generally been reported in the range of 1.8-3.5. Lower ratios are typically found in the endosperm (2.7-3.2) tissue compared to pericarp (3.4-4.2) and aleurone (3.8-4.1) outer layers of the barley grain (Izydorczyk and Dexter, 2008). Both, linear regions of repeated units of cellotriosyl or cellotetraosyl, as well as the long cellulosic oligomer blocks, have been suggested to decrease BG solubility due to chain alignment and aggregation (Burton et al., 2010; Woodward et al., 1988). Thus, the DP3/DP4 ratio provides an indication of solubility and BGs with ratios close to 1:1 are found to be more soluble than BGs with either very high or very low DP3/DP4 ratios having longer stretches with repetitive structures (Burton et al., 2010). Barley BGs typically comprise more than 1000 glucosyl residues and reported molecular mass values range 130 to $2,500 \mathrm{kDa}$. The large variations reflect the diversity of genotypical botanic origin, but also result from the methodology of extraction and molecular mass determination (Irakli et al., 2004).

A wide range of laboratory and pilot scale BG extraction protocols have been reported (Benito-Roman et al., 2011; Benito-Roman et al., 2014; Limberger-Bayer et al., 2014; Mikkelsen et al., 2013; Wood, 2010). In brief, they involve milling, inactivation of endogenous hydrolytic enzymes, extraction with hot water or alkaline solutions, removal of starch and protein using hydrolytic enzymes and/or centrifugation, recovery of BG from the extract by ethanol precipitation or cryogellation cycles and drying of the BG gum. The extractability of BG is influenced by process parameters such as fineness of grind, temperature, ionic strength and $\mathrm{pH}$ of the solvent (Mikkelsen et al., 2013). $\beta$-Glucanase activity and mechanical damage during extraction have been reported to cause BG depolymerization which modify the BG molecular mass, extraction yield and rheological behavior (Wood, 2010). Thus, valid evaluation of BG yield and quality from different barley genotypes requires identical and standardized extraction conditions. Depending on the method used, 
116 the extractability of barley BGs can vary between 33\% and 87\% (Izydorczyk and Dexter, 2008).

117 Benito-Román et al. (2011) found BG extraction yields of $\sim 73 \%$ and $\sim 62 \%$ for hulled and hulless

118 barley, respectively. Amylolytic enzymes are widely used for the degradation of starch in BG 119 extraction (Benito-Roman et al., 2014; Doehlert et al., 2012). Following thermal gelatinization the 120 starch is hydrolyzed into maltooligosaccharides, maltose and glucose by the action of endo- and 121 exo-glucanases such as $\alpha$ - and $\beta$-amylases, glucoamylase and debranching pullulanase. $\alpha$-Amylase 122 (EC 3.2.1.1) and pullulanase (EC 3.2.1.41) act endo in a pseudo random mode in the amylose and 123 amylopectin polymer chains of starch and hydrolyze $(1 \rightarrow 4)-\alpha$-D-glycosidic and $(1 \rightarrow 6)-\alpha$-D124 glycosidic linkages, respectively. At the non-reducing end of the starch polymer chains, $\beta$-Amylase 125 (EC 3.2.1.2) hydrolyses $(1 \rightarrow 4)-\alpha-\mathrm{D}$-glycosidic to liberate successive maltose, whereas 126 glucoamylase $($ EC 3.2.1.3) hydrolyses both $(1 \rightarrow 4)$ and $(1 \rightarrow 6)$ - $\alpha$-glycosidic linkages and produces 127 glucose (van Oort, 2010). For complete and efficient starch degradation, enzyme preparations with 128 specific and diverse functionalities are warranted. However, introducing more enzymes to a process 129 increases the risk of hydrolytic side-, or contaminating activities on BGs. Few studies using 130 enzymes as part of their BG isolation have investigated, if the amylolytic enzymes had any effect on 131 the BG itself (Benito-Roman et al., 2014; Doehlert et al., 2012). In the present study we screen 132 widely different barley genotypes for BG extraction yields. A hydrothermal, mechanical enzyme133 assisted protocol was optimized and we assess the risk of BG degradation by trace contaminating $\beta$ 134 glucanase side activity in commercial bulk enzyme preparations. 
136

137

138

139

140

141

142

143

144

145

146

147

148

149

150

151

152

153

154

155

156

157

158

159

\section{Materials and methods}

\subsection{Raw materials, experimental design and data analysis}

Grains from eight two-rowed spring barley genotypes having vastly different BG content were included in this work (Fig. 1). The grains of KVL408, KVL1104, CDC Fibar cv., Chameleon cv. and Columbus cv. were provided by Carlsberg Research Laboratory (Denmark) whereas Lys5f and Bomi cv. were from the University of Copenhagen (Denmark). The Lys5f, KVL1104 and KVL408 barley genotypes derive from a larger collection of barley mutants where KVL408 have been mutated in Perga and Lys5f in Bomi standard malt barley (Di Fonzo and Stanca, 1977). KVL1104 derives from the crossing of Lys5f and Bomi. CDC Fibar is a high fiber, 0\% amylose hulless barley registered in Canada. Chameleon is a hulless and Columbus a hulled standard malt barley registered in Denmark. Pearling of Columbus was performed on a vertical polishing BSPB (Bühler AG, Switzerland) with pearling $11 \%$ of husk. In total, 48 samples were prepared from mashing grains from the eight barley lines with three different enzyme combinations in replicate. Raw grains were investigated for BG content and BG spatial distribution in the grain. BG extracts were analyzed for viscosity, BG yield and molecular mass. Ethanol precipitated BGs from extracts were analyzed for DP3/DP4 ratios. Commercial amylolytic enzymes were examined for BG hydrolytic side activity (Fig. 1).

Data were mined by multivariate data analysis using principal component analysis (PCA) to visualize trends related to genotype, molecular structure and processing. PCA captures the major variation in a data set in a model $\left(\mathrm{X}=\mathrm{T} \cdot \mathrm{P}^{\prime}+\mathrm{E}\right)$ where the two-dimensional data matrix $(\mathrm{X})$ containing information about samples and variables is decomposed into systematic variation ( $\mathrm{T}$ and $\mathrm{P}^{\prime}$ ) and noise (E). The systematic variation is described by the calculated principal components (PCs) that represent the outer product of scores (containing information about the samples) and loadings (containing information about the variables) (Wold et al., 1987). PCA on the physico- 
160 chemical properties of the $48 \mathrm{BG}$ extracts was performed using Latentix software (LatentiX ${ }^{\mathrm{TM}} 2.12$,

161 Latent5, Copenhagen, Denmark, www.latentix.com). Data were auto-scaled prior to analysis.

162

163

164

165

166

167

168

169

170

171

172

173

174

175

176

177

178

179

180

181

182

183

184

\subsection{Microscopy}

Barley grains were trimmed with a razor blade to aid diffusion of agents, fixed for $24 \mathrm{~h}$ in Karnovsky's fixative (5\% glutaraldehyde, $4 \%$ paraformaldehyde, $0.1 \mathrm{M}$ sodium cacodylate buffer at pH 7.3) including a $1 \mathrm{~h}$ vacuum treatment, and subsequently washed in cacodylate buffer and water. Samples were dehydrated in a graded acetone series, infiltrated with increasing ratios of Spurr resin:acetone and embedded in Spurr resin within flat molds. The resin was polymerized in an oven at $60^{\circ} \mathrm{C}$ for $8 \mathrm{~h}$. Semi-thin sections of $2 \mu \mathrm{m}$ were cut with a histo-diamond knife on a Reichert-Jung supernova ultramicrotome and stained for BGs with $0.01 \%(\mathrm{w} / \mathrm{v})$ Calcofluor White M2R (SigmaAldrich) and imaged with UV excitation and blue emission. Other sections were stained with Periodic Acid Sciffs's (PAS) and counterstained with Amido Black (AB). All images, apart from the overview images, were taken from the central part of the starchy endosperm tissue. Sections were viewed in a Nikon Eclipse 80i light and fluorescence microscope and images were recorded with $4 \mathrm{x}$ dry objective or $100 \mathrm{x}$ objective using immersion oil. Final image processing, cropping and mounting of the images were done with Adobe (San Jose, CA, US) Photoshop CS2 and Illustrator CS2.

\subsection{Extraction and enzymatic treatment}

BG extraction yield was optimized in a mashing pre-study with focus on milling particle size, solvent:flour ratio, $\mathrm{pH}$, temperature and extraction time using the Lys5f line as model. Enzymes were dosed as suggested by the manufacturer $(1.5 \% \mathrm{w} / \mathrm{w}$, enzyme/flour). Production of high BG wort was performed using a Lochner electronic mashing device with 8 beakers. Barley grains were milled immediately before mashing with an EBC mill adjusted to $0.5 \mathrm{~mm}$. The water:flour ratio was

Mette Skau Mikkelsen, Journal of Cereal Science 
$185 \quad$ 1:15 per weight equivalent to $27 \mathrm{~g}$ barley flour mashed-in with $400 \mathrm{ml}$ standard brewing water in a

$186500 \mathrm{ml}$ metal beaker and the $\mathrm{pH}$ was adjusted to 5.5 with phosphoric acid. To facilitate starch

187 hydrolysis three different enzyme treatments were used: Termamyl ${ }^{\circ}$ SC containing thermostable $\alpha$ 188 mylase $(\mathbf{T})$, a combination of Termamyl ${ }^{\circledR}$ SC and Attenuzyme ${ }^{\circledR}$, the latter containing 189 glucoamylase (TA) or a combination of Termamyl® SC and Attenuzyme® Flex, the latter 190 containing glucoamylase and pullulanase (TAF). All enzymes were purchased from Novozymes $191 \mathrm{~A} / \mathrm{S}$, Denmark. Following $45 \mathrm{~min}$ incubation at $65^{\circ} \mathrm{C}$, the temperature was linearly increased to $19290^{\circ} \mathrm{C}$ for $25 \mathrm{~min}$, and finally kept at $90^{\circ} \mathrm{C}$ for 30 minutes. The mash was centrifuged at $3500 \mathrm{rpm}$

193 for $10 \mathrm{~min}$ to remove insoluble spent grain material. From the $340 \mathrm{ml}$ wort sample, $100 \mathrm{ml}$ were 194 withdrawn and subjected to ethanol precipitation by adding $100 \mathrm{ml}$ ethanol at room temperature, 195 incubating for precipitation $30 \mathrm{~min}$ and draining BG gums. The BG gums were lyophilized for $24 \mathrm{~h}$ 196 and ground prior to DP3/DP4 analysis of pure BG samples free of maltose and glucose. The 197 remaining wort was used directly for analyses of viscosity, BG content and molecular mass.

198

\section{4. $\beta$-Glucan content and viscosity}

The content of BGs in wort and barley grains was measured by the fluorimetric calcofluor-method (Brewing EBC standards, 1994). Calcofluor has the capacity to form fluorescent products with BGs larger than approx. 10-30 kDa present in solution and its fluorescence proportionally increases with the content of BG bound (Rieder et al., 2015). The instrument used was a BG Carlsberg System 5700 Analyzer with flow injection (Tecator, Sweden). The viscosity was measured by a viscometer Vibro SV-10 (A\&D Company Limited, Tokyo) at $20^{\circ} \mathrm{C}$ within $1 \mathrm{~h}$ after centrifugation of the wort.

The viscometer cup was filled up with $10 \mathrm{ml}$ of wort and the viscosity recorded as $\mathrm{mPas}$ at $30 \mathrm{~Hz}$ constant frequency and less than $1 \mathrm{~mm}$ amplitude.

\subsection{Molecular mass and oligomer block structure}

Mette Skau Mikkelsen, Journal of Cereal Science 
210 The molecular mass analysis was conducted by size exclusion chromatography (SEC). Prior to 211 analysis the wort samples were heated at $80{ }^{\circ} \mathrm{C}$ for $30 \mathrm{~min}$ and diluted 1:4 in $50 \mathrm{mM}$ ammonium 212 formate buffer of $\mathrm{pH}$ 5. The solutions were mixed, heated at $80^{\circ} \mathrm{C}$ for $30 \mathrm{~min}$, centrifuged and 213 filtered $(0.45 \mu \mathrm{m})$ before injection of $50 \mu 1$. Separation was performed using an Asahipak GS 214 520HQ $(7.5 \times 300 \mathrm{~mm})$ column (Shodex, US). The column was calibrated with five BG standards; 215 barley $650,000 \mathrm{kDa}$, oat $391,000 \mathrm{kDa}$, oat 265,000 kDa, barley 229,000 kDa, oat 70,600 kDa and 216 oat $35600 \mathrm{kDa}$ (Megazyme, Ireland). Elutions were performed with $50 \mathrm{mM}$ of ammonium formate 217 buffer $(\mathrm{pH} \mathrm{5})$ and $0.01 \% \mathrm{NaN}_{3}$ at $60^{\circ} \mathrm{C}$ with a constant flow rate of $0.5 \mathrm{ml} / \mathrm{min}$. The separation was 218 performed using a GPC system (viscotek 270max, Malvern) equipped with an online degasser, a 219 pump and a differential refractometer controlled at $40^{\circ} \mathrm{C}$. Data for molecular mass determinations was analyzed by Omnisec software (version 4.7.0.406, Malvern) based on conventional calibration of homopolymers. Results are reported as weight average molecular mass $\left(\mathrm{M}_{\mathrm{w}}\right)$.

The DP3/DP4 analysis was based on lichenase digestion of BG precipitated from wort prepared as described above. BG powder $(2.5 \mathrm{mg})$ was wetted with $10 \mu \mathrm{l} 50 \% \mathrm{EtOH}$, and the slurry was suspended in $500 \mu \mathrm{l}$ of $10 \mathrm{mM} \mathrm{NaH}{ }_{2} \mathrm{PO}_{4} / \mathrm{Na}_{2} \mathrm{HPO}_{4}$ buffer. The solution was heated at $96^{\circ} \mathrm{C}$ for $2 \mathrm{~h}$, cooled to $60^{\circ} \mathrm{C}$ and $10 \mathrm{U}$ of lichenase (Megazyme, Ireland) were added. The samples were incubated with mixing overnight at $60^{\circ} \mathrm{C}$. Subsequently, the enzyme was inactivated at $100^{\circ} \mathrm{C}$ for $30 \mathrm{~min}$ and the samples were lyophilized. The BG fragments were labeled with the fluorophore Aminobenzamide (2-AB) by a reductive amination procedure (Walther et al., 2015). To the lyophilized samples was added $150 \mu \mathrm{l}$ of $1 \mathrm{M} 2-\mathrm{AB}$ in DMSO/AcOH (7:3) and $150 \mu \mathrm{l}$ of $1 \mathrm{M}$ $230 \mathrm{NaBH} 3 \mathrm{CN}$ in DMSO/AcOH (7:3). Samples were mixed and incubated for $4 \mathrm{~h}$ at $60^{\circ} \mathrm{C}$, cooled to 231 room temperature, centrifuged and diluted 400-fold with a mixture of Milli Q water and acetonitrile 232 (22:78). The samples were directly analyzed by hydrophilic interaction liquid chromatography 233 (HILIC) using maltotriose and maltotetraose as standards. $5 \mu 1$ aliquots were injected onto a Waters 234 Acquity UPLC System equipped with a fluorescence detector (excitation wavelength of $350 \mathrm{~nm}$ and 
235

236

237 238

240

emission wavelength of $420 \mathrm{~nm}$ ) and columns: a VanGuard BEH glycan $1.7 \mu \mathrm{m}, 2.1 \times 5 \mathrm{~mm}$ precolumn and an Acquity UPLC BEH glycan $1.7 \mu \mathrm{m}, 2.1 \times 150 \mathrm{~mm}$ column. Measurements were performed at room temperature. Data were processed using MassLynx V4.1.

\subsection{NMR spectroscopy}

The possible presence of trace $\beta$-glucanase activity in the three different commercial enzyme mixtures applied in the wort production was tested using medium viscosity barley BG (200 kDa, Megazyme, Ireland). The BG was dissolved by gentle heating and whirl-mixing to concentrations of $1 \mathrm{mg}$ in $600 \mu \mathrm{l}$ of $50 \mathrm{mM}$ potassium phosphate buffer $\left(\mathrm{pH} \mathrm{6}\right.$ ) in $\mathrm{D}_{2} \mathrm{O}$ (Cambridge Isotope Laboratories, Andover, MA, USA). Buffer of the desired $\mathrm{pH}$ had been prepared by lyophilization and re-dissolution in $\mathrm{D}_{2} \mathrm{O}$. To three substrate samples $0.5 \mu \mathrm{l}$ of enzyme solution (Termamyl® $\mathrm{SC}$, Attenuzyme ${ }^{\circledR}$, or Attenuzyme ${ }^{\circledR}$ Flex) were added, respectively. Reactions were followed in situ by high resolution nuclear magnetic resonance (NMR) spectroscopy for $240 \mathrm{~min}$ at $18^{\circ} \mathrm{C}$ to slow down the reaction relative to process conditions. Spectra were acquired as a time series in situ by sampling 16,384 complex data points during an acquisition time of $1.57 \mathrm{sec}$, summing 32 transients and using a recycle delay of $2 \mathrm{sec}$.

The site-specific action of trace $\beta$-glucanase activity was investigated using a Lys5f BG sample extracted solely by Termamyl ${ }^{\circledR}$ SC under real process conditions, i.e. at $65^{\circ} \mathrm{C}$. Homonuclear ${ }^{1} \mathrm{H}-{ }^{1} \mathrm{H}$ DQF COSY spectra were recorded on enzyme-treated samples using a 800 MHz Bruker Avance II (Fällanden, Switzerland) NMR spectrometer equipped with a TCI cryoprobe and 18.7 T magnet (Oxford Magnet Technology, Oxford, UK). Spectra were acquired as a matrix of $2048 \times 256$ complex data points sampling $512 \mathrm{~ms} \times 64 \mathrm{~ms}$ in the two proton dimensions. Spectra were processed with extensive zero filling in both dimensions. BG structures formed by exposure to Attenuzyme ${ }^{\circledR}$ Flex were analyzed. Assignments of cleavage site signals from intermediates and products were conducted through comparison of the $2 \mathrm{D}$ spectra using 
reference assignments from previous work (Petersen et al., 2013). All spectra were acquired, 261 processed and analyzed using Topspin 2.1 (Bruker).

\section{Results and discussion}

\subsection{Raw materials}

Barley raw materials showed significant variation in the content of BG (Fig. 1) with Lys5f and KVL408 ranging 11.8-15.3\% (dry mass, dm), KVL1104 and CDC Fibar ranging 8.0-8.9 \% (dm) and Bomi, Chameleon, Columbus and Columbus pearled ranging 3.9-4.9\% (dm). Accordingly, the barley lines were categorized into high, medium or low BG genotypes. The pearling of Columbus grains increased the BG content from 3.9 to $4.5 \%$ (dm).

The distribution and appearance of BG within the barley outer layers and starchy endosperm was investigated by histochemical analyses of the eight genotypes (Fig. 2). Three kernels of each genotype were prepared for light microscopy and the results shown are consistent for all repetitions. BG is known to be the main cell wall constituent (70\%) of barley starchy endosperm and is also part (20\%) of the aleurone layer, and can be stained with calcofluor. Calcofluor also labels cellulose, which however only makes up $2 \%$ of the barley grain cell walls (Burton et al., 2010). As deduced from the calcofluor fluorescence (Fig. 2), the cell walls in the starchy endosperm appear significantly thicker in Lys5f and KVL408 (Fig. 2C, D) compared to the other lines. The cell wall signal is also fairly strong in KVL1104, CDC Fibar and Bomi (Fig. 2E, F, G), compared with Chameleon, Columbus and Columbus pearled (Fig. 2H-J). Thus, the visual appearance of the BG in the microscope is consistent with the content of BG in the different lines. Microscope samples of Lys5f and Bomi were furthermore stained for the presence of insoluble polysaccharides and counter stained with a protein stain. Starch granules from Lys5f were of similar size and distribution as those of Bomi however empty voids were frequently seen in the center of Lys5f starch granules (Fig 
2K). No differences in protein amount could be noted. The empty center of starch granules in Lys5f might be related to the general decreased starch content in this mutant line (Munck et al., 2004).

\section{2. $\beta$-Glucan extractability and oligomer block structure}

To meet the requirements of the BG health claims of FDA and EFSA a BG extract should provide 3 $\mathrm{g} \mathrm{BG} /$ day from at least $1 \mathrm{~g} /$ serving. This implies that a concentration of $4 \mathrm{~g} \mathrm{BG} / 1$ from $3 \times 250 \mathrm{ml}$ typical portion sizes sufficiently will supply the recommended dose. From Fig. 3A it can be seen that Lys5f, KVL408, KVL1104 and CDC Fibar extracts exceed this threshold whereas Bomi, Chameleon and Columbus extracts, regardless of the enzyme treatment, contain lower concentrations. Benito-Roman et al. (2014) extracted 2-4 g BG/l (239 kDa) from barley bran using ultrasound extraction, enzymatic starch hydrolysis and membrane filtration. In comparison, our extraction process provides higher BG solution concentrations from simple hot water extraction, enzymatic starch hydrolysis and centrifugation.

The effect of the different enzyme treatments was evaluated in terms of extractability defined as the recovery of BG from the total amount found in the barley grain. For most barley lines the intensification of enzyme treatment did not influence the genotypic BG extractability significantly. The extractability for T, TA and TAF samples was in the range of 41-81\%, 47-79 \% and 60-100\%, respectively (Fig. 3B). These numbers are similar or slightly higher (for Lys5f and KVL408 TAF extracts) compared to extraction yields reported elsewhere (Benito-Roman et al., 2011; Izydorczyk and Dexter, 2008). Unlike Benito-Román et al. (2011), we did not find lower extractability for the hull-less barley lines (CDC Fibar and Chameleon) and we did not see an increase in BG yield from the pearling treatment of the Columbus grains, which have been indicated by others (Baik and Ullrich, 2008). From Fig. 3B, a clear tendency of higher extractability from barley lines containing BGs with low DP3/DP4 ratios can be seen. This is in good agreement with the general understanding of the effect of BG non-repetitive oligomer block structure on polymer solubility 
309

310

311

312

313

314

315

316

317

318

(Burton et al., 2010). For Lys5f, KVL408 and KVL1104 with high DP3/DP4 ratios of 3.8, 3.8 and 3.2, respectively, the T and TA BG yields reached only 41-68\% of the potential extraction levels indicating a lower releasability of BG from these grains. Nevertheless, when comparing all barley lines and enzyme treatments, the combination of either Lys5f or KVL408 high BG raw materials with the TAF enzyme treatment resulted in the overall highest extractabilities. Thus, the Lys5f and KVL408 TAF extractions meet important material and method requirements for preparing an extract having a high content of natural BG.

\subsection{Molecular mass and viscosity}

The $\mathrm{M}_{\mathrm{w}}$ of extracted barley BGs calculated from equivalent external BG standards is shown in Fig. 3C. The highest $M_{w}$ values were found for Lys5f, KVL408 and KVL1104 samples with values ranging 570-580 $\mathrm{kDa}(\mathrm{T}), 415-535 \mathrm{kDa}(\mathrm{TA})$ and 40-110 $\mathrm{kDa}$ (TAF). In comparison, the CDC Fibar, Bomi, Chameleon and Columbus BGs from T, TA, and TAF extractions showed significantly lower $\mathrm{M}_{\mathrm{w}}$ values of $155-415 \mathrm{kDa}, 130-270 \mathrm{kDa}$ and $15-35 \mathrm{kDa}$, respectively. In a previous study (Mikkelsen et al., 2013), we extracted Lys5f and Bomi BGs in large scale using thermostable $\alpha$ amylase, protease, wet milling, repeated heat cycles (up to $125^{\circ} \mathrm{C}$ ), decanting plus centrifugation and ethanol precipitation and found the $\mathrm{BG}_{\mathrm{w}}$ from the two barley lines to be similar (200-300 $\mathrm{kDa}$ ). In the present study, the genotypic variation in $\mathrm{BG} \mathrm{M}_{\mathrm{w}}$ observed by others (Irakli et al., 2004) is supposedly better preserved due to the more gentle extraction conditions. It is obvious that extraction with some amylolytic enzyme preparations resulted in BG depolymerization (Fig. 3C).

This effect could either be due to contaminating activities in the commercial enzyme preparations or due to amylolytic enzymes themselves exhibiting nonspecific activities toward the BG (Doehlert et al., 2012). The degree of $\mathrm{BG}$ degradation followed the order $\mathrm{T}<\mathrm{TA}<\mathrm{TAF}$, and a profound reduction in $\mathrm{M}_{\mathrm{w}}$ was especially found for the TAF combination, where $\alpha$-amylase is combined with glucoamylase and pullulanase. The elution profiles of Lys5f and Bomi T, TA, and TAF samples

Mette Skau Mikkelsen, Journal of Cereal Science 
334 shown in Fig. 4 represent the general trend in sample polydispersity as affected by the different 335 enzyme combinations. In addition to peaks eluting in the order T > TA > TAF due to decreasing $336 \mathrm{M}_{\mathrm{w}}$, the polydispersity index $\left(\mathrm{M}_{\mathrm{w}} / \mathrm{M}_{\mathrm{n}}\right)$ increased in the order $\mathrm{T}<\mathrm{TA}<\mathrm{TAF}$, indicating a 337 broadening of the molecular mass distribution in the samples as a result of intensified enzymatic 338 treatment. In a similar study Doehlert et al. (2012) found starch hydrolytic enzymes to have a large 339 effect on the $\mathrm{M}_{\mathrm{w}}$ and polydispersity when used for maximizing the extractability of oat BGs. Hence, 340 efficient BG extractability and recovery must be balanced against $M_{w}$ loss of the extracted BG 341 when using existing enzyme preparations. High extractability and low $\mathbf{M}_{\mathrm{w}}$ is advantageous for 342 beverage applications since high viscosity is unsuited for these applications. The wort viscosity 343 generally followed the $\mathrm{M}_{\mathrm{w}}$ of the samples (Fig. 3C). Thus, a significant drop in viscosity was seen 344 for TAF samples (2-12 mPas) as compared to T (5-296 mPas) and TA (4-216 mPas) samples, 345 respectively.

346 It should be noted that the calcofluor method for BG quantification, albeit being rapid and 347 suitable for liquid samples, is not accurate for low molecular mass (<10-30 kDa) BGs. The assay 348 problem implies that the BG content of the TAF samples, being generally low in $B G M_{w}$, could be 349 somewhat underestimated. This might be the reason why CDC Fibar, Bomi, Chameleon and 350 Columbus TAF (17-35 kDa) extractabilities compared to Lys5f, KVL408 and KVL1104 (42-109 $351 \mathrm{kDa}$ ) are relatively lower when compared internally to the $\mathrm{T}$ and TA extraction yields (Fig. 3B).

The BG extracts generally showed high variability in their physico-chemical properties 354 (supplemental table S1) as illustrated by the PCA bi-plot (Fig. 5). The samples typically distribute 355 along the diagonals of the plot according to high, medium and low BG barley lines or enzymatic 356 treatment (T, TA, TAF). Inspection of the loadings (Fig. 5) shows that the main variance among 357 samples (PC1, 53\%) is explained both by differences in structural features like DP3/DP4 ratio and 358 molecular mass and by BG content in the raw materials. Due to general viscosity dependence of $\mathrm{M}_{\mathrm{w}}$ 
359

360

361

362

363

364

365

366

367

368

369

370

371

372

373

374

375

376

377

378

379

380

381

382

383

the clustering of these variables was expected and the apperent co-variance between high BG content in raw materials and high DP3/DP4 ratios of the extracted BG has been suggested by others (Burton et al., 2011). The main target of the Lys5f mutation is suggested to be in starch biosynthesis, decreasing starch content in the endosperm (Patron et al., 2004) and the effects on BG deposition have been explained as pleitropic. This implies that a redirection of glucose incorporation into alternative carbohydrate biosynthesis pathways may take place. In addition to the thicker cell walls found in Lys5f compared to its mother line Bomi (Fig. 2), more BGs were allocated to the outer parts of the grain. Here, the more recalcitrant BGs with high DP3/DP4 ratio are typically found (Izydorczyk and Dexter, 2008), which may explain the overall higher DP3/DP4 ratio found for the Lys5f BGs. The minor variance along PC2 (33\%) explained by extractability and $\mathrm{M}_{\mathrm{w}}$ is spanned by TAF and T/TA samples. This finding confirms that BG depolymerization events, especially originating from the Attenuzyme ${ }^{\circledR}$ Flex enzyme side activity, modify the BG extractable amount.

\subsection{Side activity from amylolytic enzymes}

The molecular mass profiles of the BGs were affected by the amylolytic enzymes, especially by the Attenuzyme ${ }^{\circledR}$ Flex mixture. Hence, NMR spectroscopy was used to investigate the products generated by the $\beta$-glucanase activities in the commercial enzyme preparations. Using pure medium viscosity barley BG from Megazyme as the substrate, the highest $\beta$-glucanase side activity was found in Attenuzyme ${ }^{\circledR}$ Flex (Fig. 6A) followed by Attenuzyme®. No significant $\beta$-glucanase activity was observed in Termamyl® SC. Enzyme activity was judged by the emergence of reducing end signals other than glucose (present in the enzyme mixtures), as indicated in Fig. 6A.

The assignments in Fig. 6B show that the vastly predominating cleavage site signals can be attributed to $\beta-(1-3)$ reducing end signals, formed by cleavage with an endo-1,3-1,4- $\beta$-D-glucanase activity in Attenuzyme ${ }^{\circledR}$ Flex and Attenuzyme ${ }^{\circledR}$ preparations. The substrate sample (BG from

Mette Skau Mikkelsen, Journal of Cereal Science 
384

385

386

Lys5f) was largely devoid of pullulan and amylopectin substrates due to Termamyl® SC (amylase) pretreatment and subsequent ethanol precipitation in the preparation of the dry BG powder fraction. Thus, the use of high-resolution NMR spectroscopy provides atomic resolution to validate residual $\beta$-glucanase activity in Attenuzyme ${ }^{\circledR}$ Flex and Attenuzyme ${ }^{\circledR}$ preparations, which can be, from cleavage site structures (Petersen et al., 2013), identified as a Lichenase (EC 3.2.1.73) activity (Fig. 6C). The presence of this activity rationalizes the rapid decay of BG molecular masses due to its endoglucanase activity. In this specific case, the presence of minor $\beta$-endoglucanase activity is considered advantageous, since is permits a controlled minor degradation of the barley BGs to increase extractability and decrease viscosity.

\section{Conclusion}

The genotypic variation in barley grain BG content and molecular structure in combination with enzymatic modifications directs its potential as an ingredient in a natural extract high in BG. Lys5f and KVL408 high BG lines extracted with combined $\alpha$-amylase, glucoamylase and pullulanase enzymes meet optimal material, methods and product requirements. The extracts demonstrate extraordinary high BG yields meeting the criteria for the EFSA and FDA barley BG health claims, low viscosity ( 10 mPa s) and molecular mass values ( 100 kDa) comparable to commercial barley BG products. Lichenase side activity from the amylolytic enzymes cause controlled BG degradation, which increases the extractable amount and provides desired viscosity.

\section{Acknowledgements}

The Innovation Fond Denmark is greatly acknowledged for financial support to the project “LIQFUN”. Microscopy data were collected at the Center for Advanced Bioimaging (CAB) Denmark, University of Copenhagen. 


\section{Reference List}

Baik, B.K., Ullrich, S.E., 2008. Barley for food: Characteristics, improvement, and renewed interest. J. Cereal Sci. 48, 233-242.

Benito-Roman, O., Alonso, E., Lucas, S., 2011. Optimization of the beta-glucan extraction conditions from different waxy barley cultivars. J. Cereal Sci. 53, 271-276.

Benito-Roman, O., Alonso, E., Palacio, L., Pradanos, P., Cocero, M.J., 2014. Purification and isolation of beta-glucans from barley: Downstream process intensification. Chem. Eng. Process. 84, 90-97.

Burton, R.A., Collins, H.M., Kibble, N.A.J., Smith, J.A., Shirley, N.J., Jobling, S.A., Henderson, M., Singh, R.R., Pettolino, F., Wilson, S.M., Bird, A.R., Topping, D.L., Bacic, A., Fincher, G.B., 2011. Over-expression of specific $\mathrm{HvCslF}$ cellulose synthase-like genes in transgenic barley increases the levels of cell wall $(1,3 ; 1,4)$-beta-D-glucans and alters their fine structure. Plant Biotech. J. 9, 117-135.

Burton, R.A., Gidley, M.J., Fincher, G.B., 2010. Heterogeneity in the chemistry, structure and function of plant cell walls. Nat. Chem. Bio. 6, 724-732.

Di Fonzo, N., Stanca, A.M., 1977. EMS derived barley mutants with increased lysine content. Genetica Agraria 31, 401-409.

Doehlert, D.C., Simsek, S., McMullen, M.S., 2012. Extraction of beta-glucan from oats for soluble dietary fiber quality analysis. Cereal Chem. 89, 230-236.

Dornez, E., Holopainen, U., Cuyvers, S., Poutanen, K., Delcour, J.A., Courtin, C.M., Nordlund, E., 2011. Study of grain cell wall structures by microscopic analysis with four different staining techniques. J. Cereal Sci. 54, 363-373.

El, K.D., Cuda, C., Luhovyy, B.L., Anderson, G.H., 2012. Beta glucan: health benefits in obesity and metabolic syndrome. J. Nutr. Metab. 2012, 851362.

FDA, 2005. 21 CFR part 101. Food labeling, Health claims; Soluble dietary fiber from certain foods and coronary heart disease. US Food and Drug Administration, Federal Register 70, 7615076162 .

Frank, J., Sundberg, B., Kamal-Eldin, A., Vessby, B., Aman, P., 2004. Yeast-leavened oat breads with high or low molecular weight beta-glucan do not differ in their effects on blood concentrations of lipids, insulin, or glucose in humans. J. Nutr. 134, 1384-1388.

Harland, J., 2014. Authorised EU health claims for barley and oat beta-glucans. In: Sadler, M.J. (Ed.), Foods, nutritions and food ingredients with authorised EU health claims, Woodhead Publihing, Salt Lake City, UT, USA, pp. 25-45.

Irakli, M., Biliaderis, C.G., Izydorczyk, M.S., Papadoyannis, I.N., 2004. Isolation, structural features and rheological properties of water-extractable beta-glucans from different Greek barley cultivars. J. Sci. Food Agric. 84, 1170-1178. 
Izydorczyk, M.S., Dexter, J.E., 2008. Barley beta-glucans and arabinoxylans: Molecular structure, physicochemical properties, and uses in food products-a Review. Food Res. Int. 41, 850868.

Kerckhoffs, D.A.J.M., Hornstra, G., Mensink, R.P., 2003. Cholesterol-lowering effect of betaglucan from oat bran in mildly hypercholesterolemic subjects may decrease when betaglucan is incorporated into bread and cookies. Am. J. Clin. Nutr. 78, 221-227.

Limberger-Bayer, V.M., de Francisco, A., Chan, A., Oro, T., Ogliari, P.J., Barreto, P.L.M., 2014. Barley beta-glucans extraction and partial characterization. Food Chem. 154, 84-89.

Mikkelsen, M.S., Jespersen, B.M., Moller, B.L., Laerke, H.N., Larsen, F.H., Engelsen, S.B., 2010. Comparative spectroscopic and rheological studies on crude and purified soluble barley and oat beta-glucan preparations. Food Res. Int. 43, 2417-2424.

Mikkelsen, M.S., Jespersen, B.M., Larsen, F.H., Blennow, A., Engelsen, S.r.B., 2013. Molecular structure of large-scale extracted beta-glucan from barley and oat: Identification of a significantly changed block structure in a high beta-glucan barley mutant. Food Chem. 136, $130-138$.

Mikkelsen, M.S., Jespersen, B.M., Mehlsen, A., Engelsen, S.B., Froekiaer, H., 2014. Cereal betaglucan immune modulating activity depends on the polymer fine structure. Food Res. Int. $62,829-836$.

Munck, L., Moller, B., Jacobsen, S., Sondergaard, I., 2004. Near infrared spectra indicate specific mutant endosperm genes and reveal a new mechanism for substituting starch with $(1 \rightarrow 3,1 \rightarrow 4)$-beta-glucan in barley. J. Cereal Sci. 40, 213-222.

Naumann, E., van Rees, A.B., Onning, G., Oste, R., Wydra, M., Mensink, R.P., 2006. Beta-glucan incorporated into a fruit drink effectively lowers serum LDL-cholesterol concentrations. Am. J. Clin. Nutr. 83, 601-605.

Patron, N.J., Greber, B., Fahy, B.E., Laurie, D.A., Parker, M.L., Denyer, K., 2004. The lys5 mutations of barley reveal the nature and importance of plastidial ADP-Glc transporters for starch synthesis in cereal endosperm. Plant Physiol. 135, 2088-2097.

Petersen, B.O., Olsen, O., Beeren, S.R., Hindsgaul, O., Meier, S., 2013. Monitoring pathways of beta-glucan degradation by enzyme mixtures in situ. Carbohydr. Res. 368, 47-51.

Rieder, A., Ballance, S., Lovaas, A., Knutsen, S.H., 2015. Minimizing molecular weight reduction of beta-glucan during barley bread making. Lwt-Food Sci. Tech. 64, 767-774.

van Oort, M., 2010. Enzymes in bread making. In: Whitehurst, R.J., van Oort, M. (Eds.), Enzymes in food Thechnology, Blackwell Publishing ltd., Ames, Iowa, USA, pp. 103-143.

Walther, A., Ravasio, D., Qin, F., Wendland, J., Meier, S., 2015. Development of brewing science in (and since) the late 19th century: Molecular profiles of 110-130 year old beers. Food Chem. 183, 227-234.

Wold, S., Esbensen, K., Geladi, P., 1987. Principal component analysis. Chemometr. Intell. Lab. 2, $37-52$. 
483 Wood, P.J., 2010. Oat and rye beta-glucan: Properties and function. Cereal Chem. 87, 315-330.

484 Woodward, J.R., Phillips, D.R., Fincher, G.B., 1988. Water-soluble $(1 \rightarrow 3,1 \rightarrow 4)$-beta-D-glucans from barley (Hordeum-Vulgare) endosperm .4. Comparison of 40-degrees-C and 65degrees-C soluble fractions. Carbohydr. Polym. 8, 85-97. 


\section{Fig. 1.}

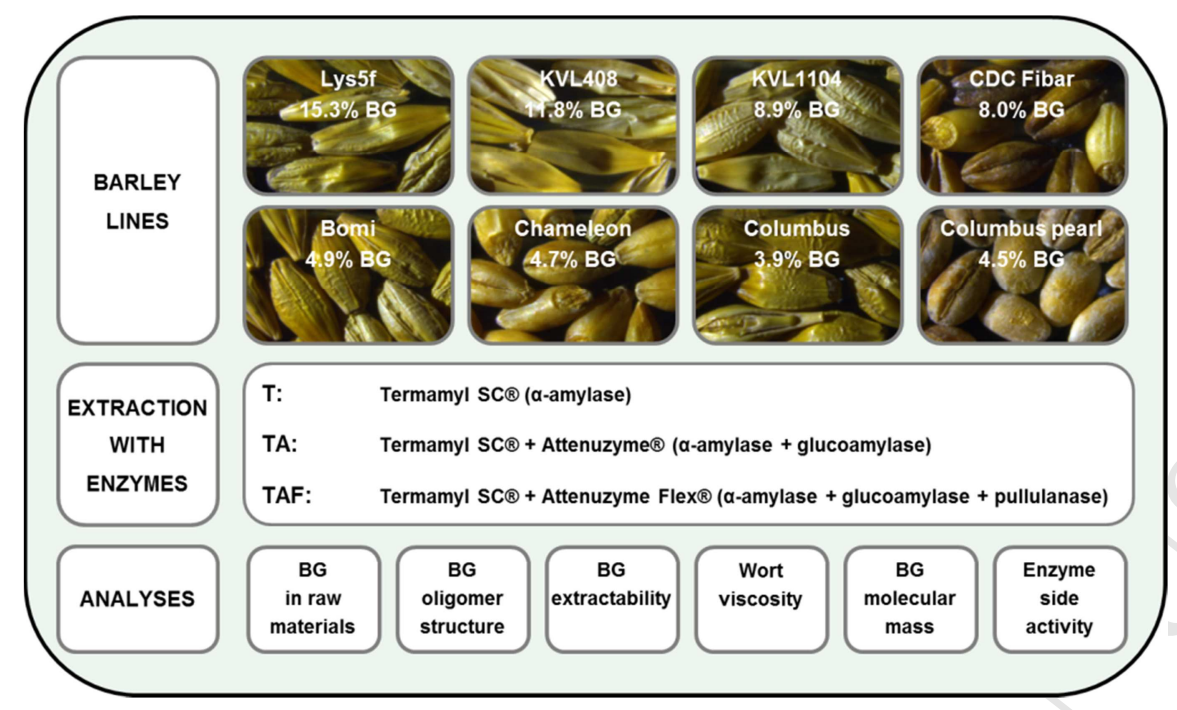

Fig.1. Study overview including eight barley genotypes, three enzyme combinations and six analysis methods. 


\section{Fig .2.}

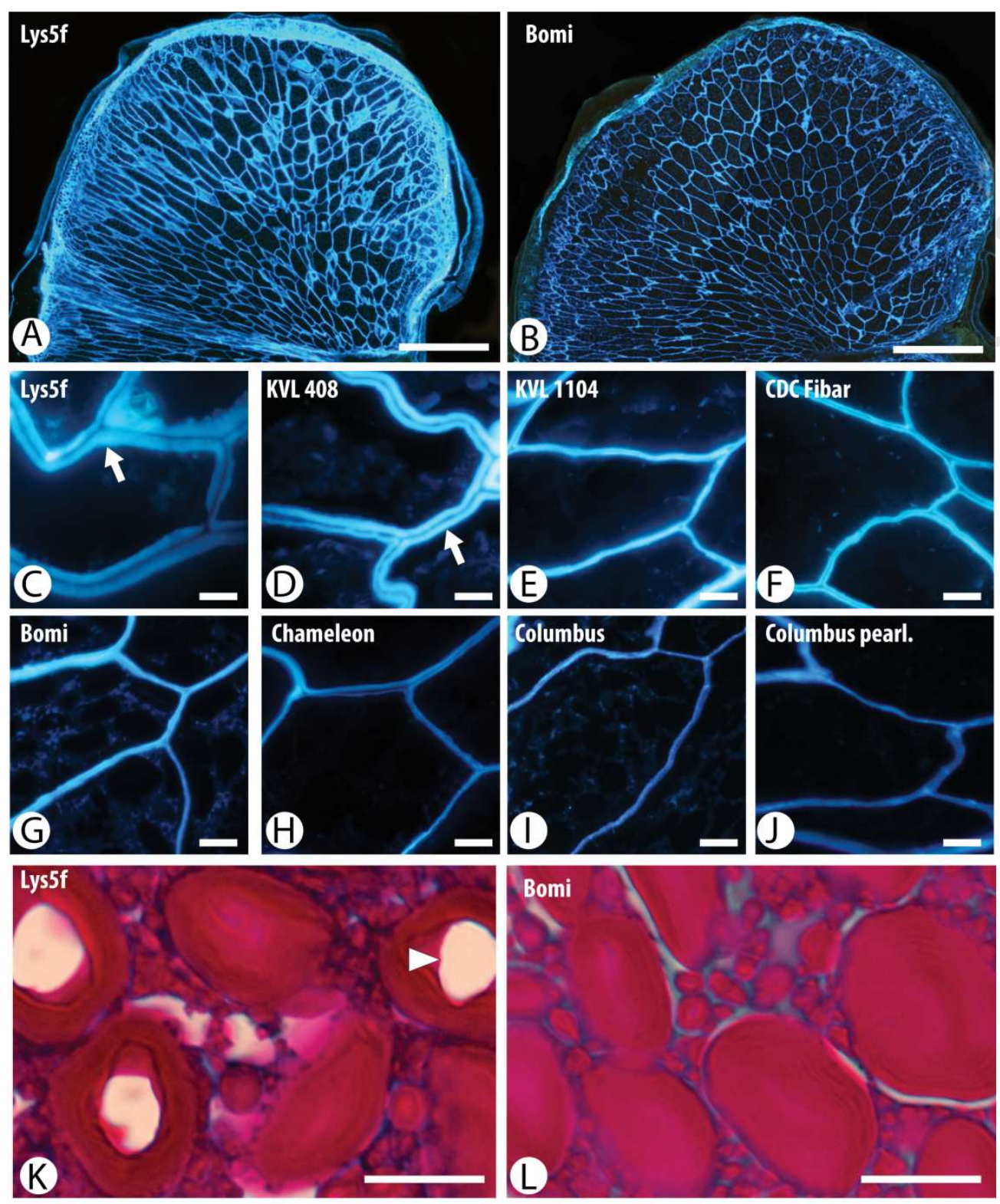

Fig. 2. Histochemical analysis of the eight barley genotypes used for extraction experiments. A and B show half kernels of Lys5f and Bomi in low magnification. C-J show details from the starchy endosperm cell wall from all the genotypes. Note the thick and less dense cell walls in Lys5f and KVL408 (arrow). In K and L the differences in starch granule structure is shown for Lys5F and Bomi. 
Note the empty voids in Lys5F (arrowhead). A-J are calcofluor stained, K and L are stained with

PAS/AB. Bar $=300 \mu \mathrm{m}(\mathrm{A}, \mathrm{B}), 10 \mu \mathrm{m}(\mathrm{C}-\mathrm{L})$. 
Fig. 3.
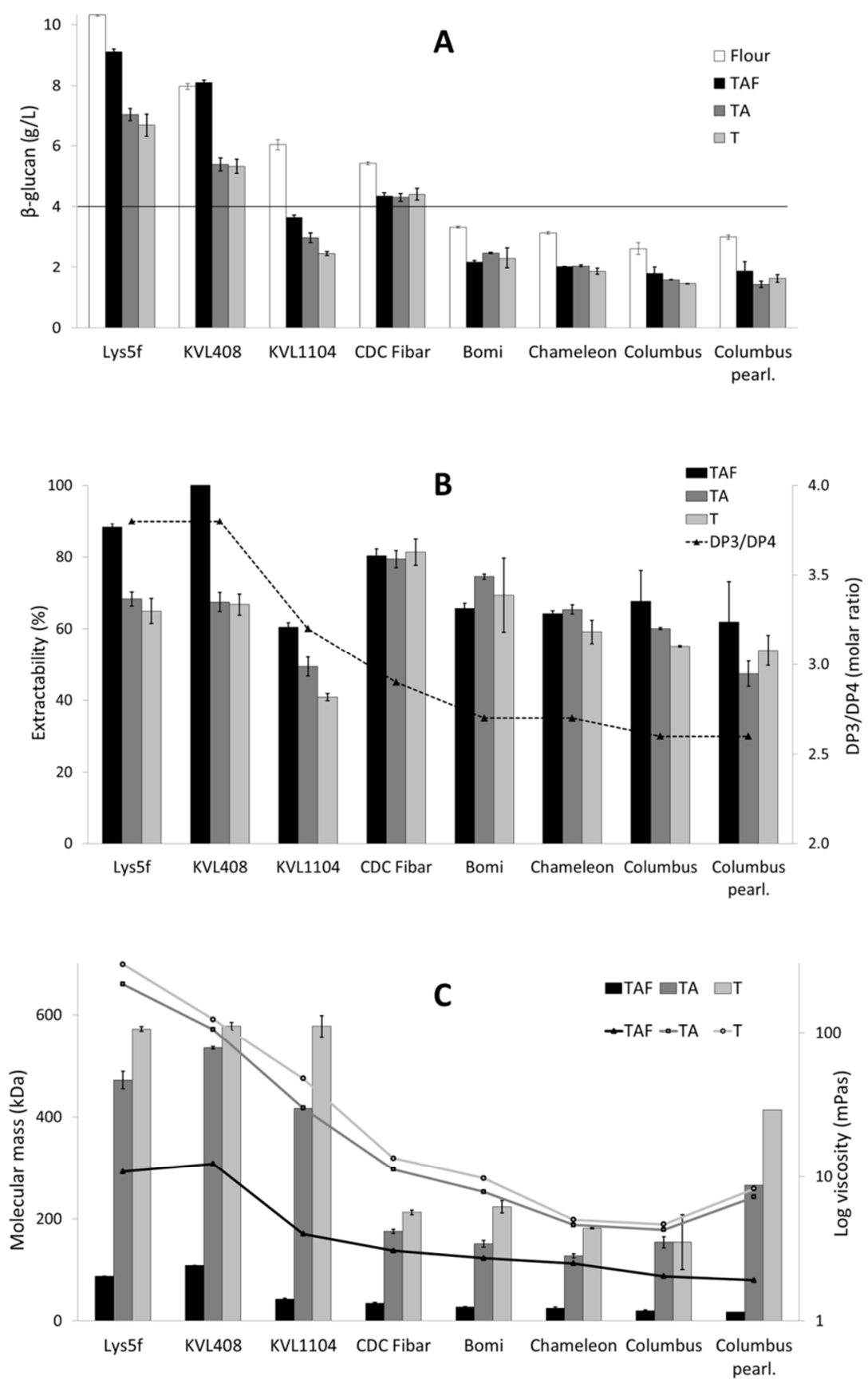

Mette Skau Mikkelsen, Journal of Cereal Science 
Fig. 3. (A) Potential and real extraction level of BG from different barley genotypes. Bar $=4 \mathrm{~g} \mathrm{BG} / \mathrm{l}$. (B) Extractability (\%) of BG from different barley genotypes in relation to oligomer block structure (DP3/DP4). (C) Molecular mass $\left(\mathrm{M}_{\mathrm{w}}\right)$ of BG from different wort in relation to wort viscosity. Mean values $\pm \mathrm{SD}, \mathrm{n}=2$. 


\section{Fig. 4.}

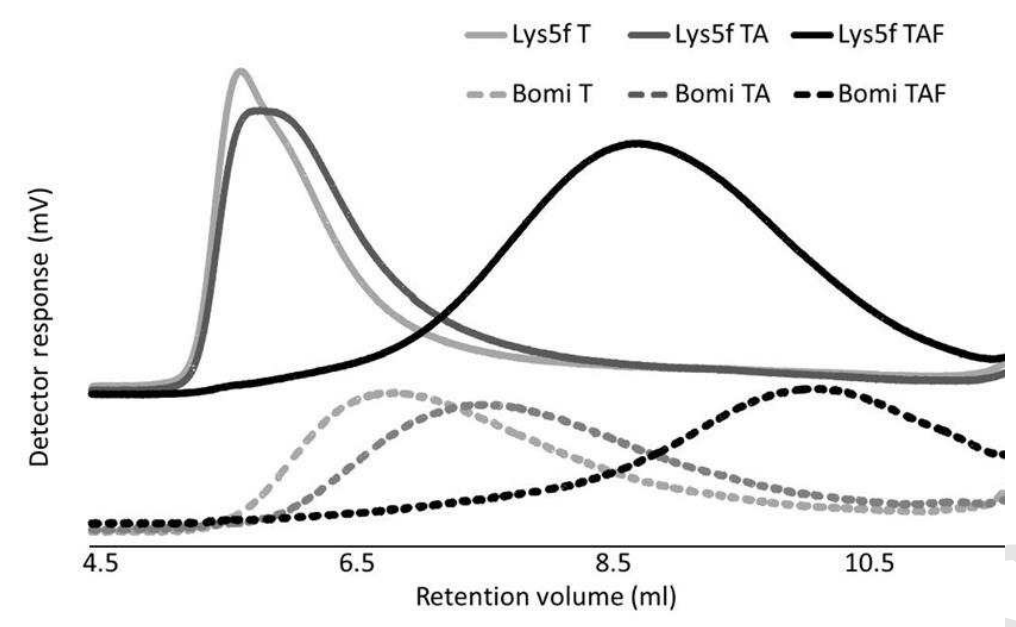

Fig. 4. The effect of T, TA and TAF amylolytic enzymes on Lys5f and Bomi BG molecular mass profiles as determined by size-exclusion chromatography. The peak widths calculated as polydispersibility indices, $\mathrm{M}_{\mathrm{w}} / \mathrm{M}_{\mathrm{n}}$ are provided in the supplemental table $\mathrm{S} 1$. 


\section{Fig. 5.}

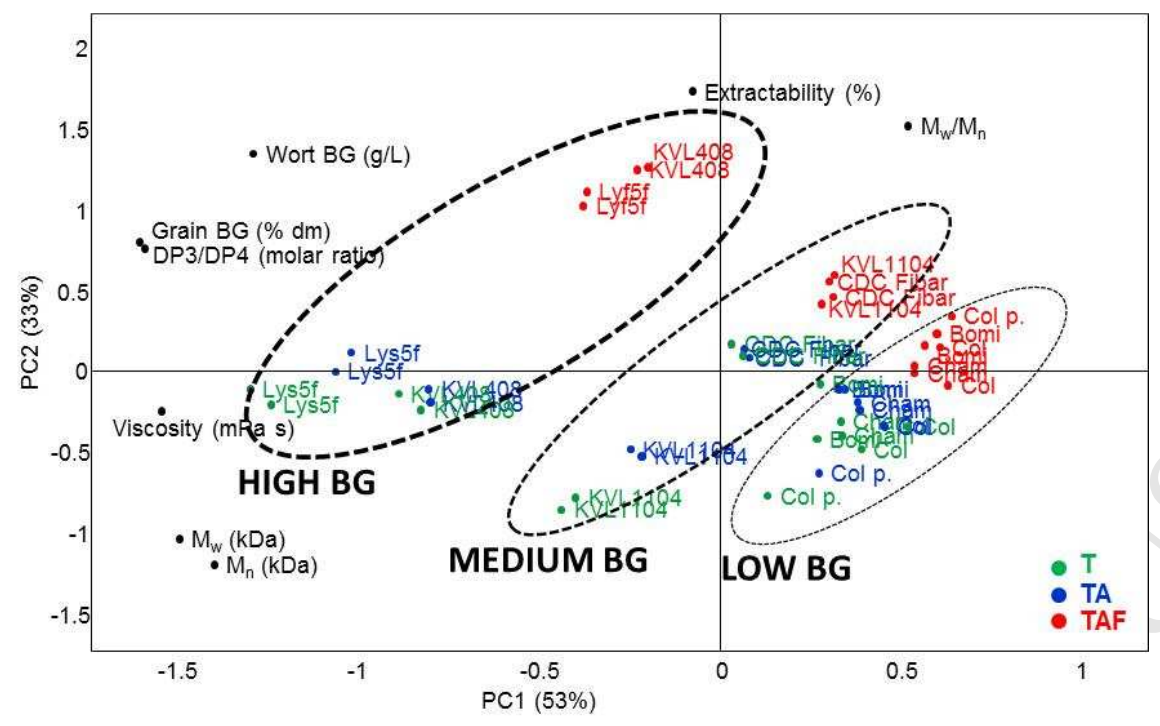

Fig. 5 PCA bi-plot based on the auto-scaled physico-chemical properties of the 48 BG extracts

(supplemental table S1). The first two principal components explain $87 \%$ of the data variance. Samples cluster according to high, medium and low BG barley lines. DP3/DP4 = triosyl/tetraosyl molar ratio, $M_{w}=$ Weight average molecular mass, $M_{n}=$ Number average molecular mass, $M_{w} / M_{n}=$ Polydispersibility index. 


\section{Fig. 6.}
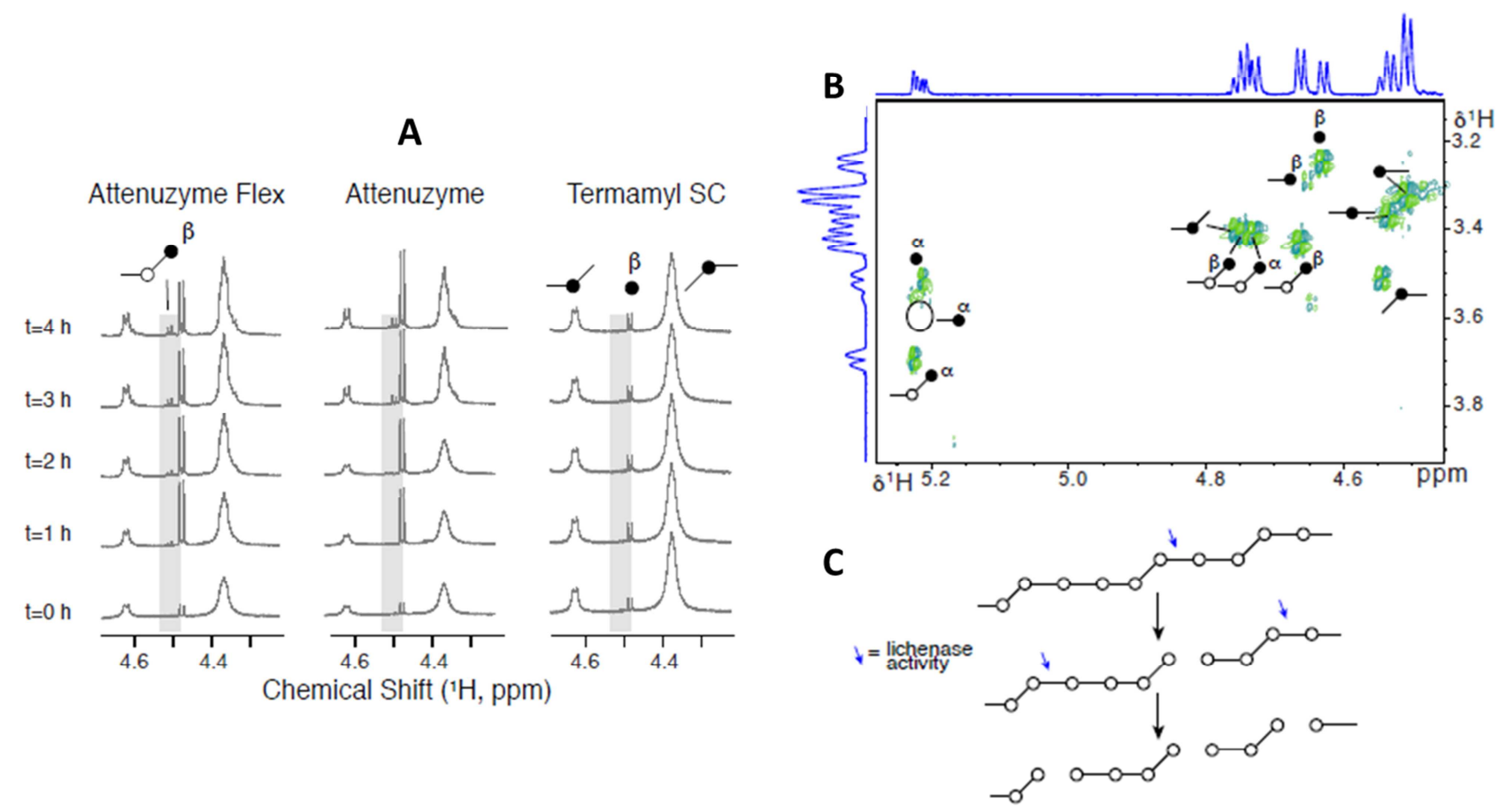

Fig. 6. (A) End products of $B G$ degradation at $18^{\circ} \mathrm{C}$ by Attenuzyme ${ }^{\circledR}$ Flex, Attenuzyme $®$ and

Termamyl® SC enzyme mixtures using medium viscosity barley BG from Megazyme as the substrate.

(B) ${ }^{1} \mathrm{H}-{ }^{1} \mathrm{H}$ COSY spectrum of Lys5f BG degraded by the Attenuzyme ${ }^{\circledR}$ Flex side activity at $65^{\circ} \mathrm{C}$. (C) Lichenase cleavage pattern on mixed linkage BGs. 


\section{Highlights}

- Screening of barley genotypes for high $\beta$-glucan (BG) extraction yields

- High BG grain content correlate with high BG triosyl/tetraosyl (DP3/DP4) molar ratio

- Lichenase side activity from amylolytic enzymes cause controlled BG degradation

- Lys5f and KVL408 barley extracts meet EFSA and FDA BG health claim criteria 